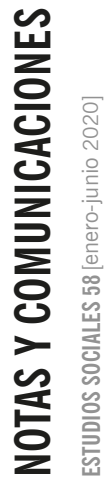




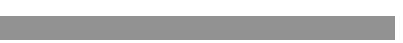




\section{LAS CONTROVERSIAS POLÍTICAS \\ Y SUS FRONTERAS ${ }^{1}$}

POLITICAL CONTROVERSIES

AND THEIR BOUNDARIES

JULIETTE RENNES ·

Centre d'Étude des Mouvements Sociaux, École des Hautes Études en Sciences Sociales (EHESS) de París (Francia).

Email: rennes@ehess.fr

\section{Registro bibliográfico}

RENNES, JULIETTE «Las controversias políticas y sus fronteras», en: ESTUDIOS SOCIALES, revista universitaria semestral, año XXX, $n^{\circ} 58$, Santa Fe, Argentina, Universidad Nacional del Litoral, enero-junio, 2020, pp. 257-283.

\author{
Descriptores · Describers \\ controversia / polémica / debate / \\ controversy / polemic / debate
}

¿Es justo, necesario, útil despenalizar el aborto y el consumo de cannabis, gravar las transacciones financieras, controlar la venta de armas de fuego, legalizar el matrimonio de parejas del mismo sexo y el derecho al sufragio a los residentes extranjeros, imponer cupos femeninos en las asambleas electas, abolir la pena de muerte? Para designar la dimensión conflictiva de estas cuestiones en muchos países en los inicios del siglo XXI en los medios o en los intercambios ordinarios pueden emplearse sucesivamente los términos "controversia», "polémica», «caso», «debate» o eventualmente "problema». En algunos campos de las ciencias humanas y sociales, esos términos designan fenómenos distintos, aunque esa distinción nunca fue estabilizada: una "polémica», por ejemplo, puede ser definida y aprehendida bajo ángulos diferentes por la sociología, la lingüística, las ciencias de la información y de la comunicación, la historia o por las diferentes corrientes de investigación internas a cada una de esas disciplinas.

1] Aparecido originalmente como: «Les controverses politiques et leurs frontières», en: Études de communication, Université Lille-3, n 47, 2016, pp. 21-47.

Traducción del francés a cargo de Ana Soledad Montero (Escuela de Política y Gobierno, Universidad Nacional de San Martín/CONICET, Argentina). 
En las disciplinas literarias y lingüísticas se privilegian los estudios de los recursos retóricos, argumentativos y lexicales de los discursos agonísticos y el análisis de los géneros discursivos dedicados a su expresión (panfleto, sátira, libelo, carta abierta, manifiesto), mientras que las ciencias de la información y la comunicación enriquecieron la comprensión de los dispositivos mediáticos que organizan las confrontaciones de puntos de vista. En los estudios de la ciencia (science studies), la dinámica de las controversias que tratan sobre asuntos cognitivos y epistemológicos en el seno de comunidades científicas es objeto de una importante literatura empírica y teórica desde los años 1980. Tanto es así que los trabajos de los estudios de la ciencia han servido ampliamente de modelo, para la sociología, para describir todo tipo de debates litigiosos, incluyendo los debates políticos evocados al inicio de este artículo, que se distinguen claramente de las controversias científicas por sus públicos y por sus implicaciones concretas para los actores sociales.

En este artículo me propongo contribuir a clarificar los solapamientos y las fronteras entre diferentes formas agonísticas y entre las perspectivas que se han desarrollado para describirlas y comprenderlas. Intento luego, más específicamente, circunscribir las cuestiones litigiosas que pueden ser calificadas de "políticas» por su formulación y por lo que ponen en juego, calificación sobre la que volveré más tarde. ¿Qué implica, desde el punto de vista epistemológico y metodológico, el hecho de tomarlas como una controversia más que como una polémica, un debate, un diferendo, un caso, una movilización o un problema público? ¿Y cuáles son las dimensiones de la conflictividad política que quedan en la sombra cuando delimitamos un corpus para analizar una controversia pública? Confrontada, en mis propias investigaciones, a estas dos preguntas relativas tanto a la categorización de las diferentes formas agonísticas públicas como a la delimitación del material de investigación, aquí expongo los análisis textuales a los que he llegado, apoyándome en una discusión con los trabajos realizados hasta el momento ${ }^{2}$.

2] Agradezco a German Fernández Vavrik y Sezin Topçu por las discusiones que hemos tenido acerca de las controversias y que contribuyeron a nutrir este artículo. 


\section{DEBATE, POLÉMICA, CONTROVERSIA}

En un capítulo incluido en un libro sobre el discurso polémico publicado en 2003, Christian Plantin constataba que «debate», "polémica» y «controversia» eran habitualmente empleados en la prensa como sinónimos dentro de un mismo artículo (Plantin, 2003). Esa constatación sigue siendo válida más de una década luego, incluso si esos tres términos son, entonces y ahora, utilizados de forma desigual: «debate» es bastante más habitual que "polémica», a su vez mucho más habitual que «controversia» ${ }^{3}$. De hecho, "debate» es un término genérico amplio o débil —un «hipergénero», en los términos de Dominique Maingueneau — ${ }^{4}$ que designa simplemente una confrontación argumentada de puntos de vista, sean cuales sean sus metas, su objeto, su situación de enunciación, su temporalidad y su grado de conflictividad: un debate puede remitir a un intercambio único o repetido varias veces, oral o escrito, estar focalizado sobre una cuestión bien determinada o abarcar una diversidad de cuestiones no definidas de antemano. Además, la naturaleza de las cuestiones que pueden ser materia de debate no se circunscribe a ningún dominio de actividad y las diferencias entre los puntos de vista de los debatidores pueden ser desde simples matices a oposiciones vividas como insuperables.

Por todas esas razones, el grado de argumentatividad de un debate es muy variable: cuando el tema del debate es considerado menor por sus protagonistas o cuando ellos/ellas no experimentan sus diferencias de punto de vista como antagonismos, el intercambio tiene pocas chances de ser estructurado por lo que Marc Angenot ha llamado «arsenales argumentativos» (ANGENOT, 20I2), es decir, argumentarios ya probados, estabilizados y consolidados por su(s) confrontación(es) anterior(es) con una serie de argumentos adversos sobre el mismo objeto.

No obstante, por más reducida que sea, es claramente la presencia de argumentos, e incluso de un cierto tipo de argumentos que se inscriben en una «gramática» de la vida política, lo que distingue el debate de otras formas dialogales

3] En la base de artículos Europresse (1088 fuentes de prensa en francés) entre el 25 de abril de 2006 y el 25 de abril de 2016 se encuentra 4,6 veces más de títulos de artículos que contienen el sintagma «debate sobre» (41 547 artículos) «que polémica sobre» (8890 artículos), y 20,8 más que «controversia sobre» (1995 artículos). La menor frecuencia del término «controversia» se observa también en un corpus temático vinculado a los debates sobre el clima (SCOTTO D’APOLLONIA et al. 2014).

4] Un hipergénero es un modo de organización textual de débiles restricciones («diálogo», «carta», etc.) que se encuentra en épocas y lugares muy diversos (MAINGUENEAU, [1996] 2009: 73). 
no agonísticas como la simple conversación. En una conversación ordinaria, está admitido que un locutor o una locutora justifique una posición subjetiva sólo por su relación vivida y singular con respecto a la cuestión planteada («me gusta tal música porque mis padres la escuchaban cuando yo era niño»). Por el contrario, para que haya «debate», debe proveer razones para adherir, preferir o actuar que estén desvinculadas de su situación particular («me gusta tal música porque tiene tal o cual cualidad»). Y es precisamente esa forma de «desingularización» (BOLTANSKI, 1984) lo que hace de una posición algo susceptible de ser discutido.

Ese trabajo argumentativo es menos definitorio en los intercambios designados como «polémica»: en el corpus de prensa estudiado por Christian Plantin los periodistas optan por ese término cuando perciben, en una confrontación discursiva sobre una determinada cuestión, «emociones violentas del orden de la cólera o la indignación» (PLANTin, 2003, p. 406). En los trabajos de historia literaria y de análisis retórico, sea que se considere la polémica como una subcategoría del hipergénero «debate» o como un género distinto, ésta siempre se caracteriza por la «virulencia» de la expresión de las oposiciones entre los polemistas (profesionales) o entre los «polemizadores» (ordinarios) sobre una cuestión dada (KERBRAT-ORECCHIONI, I980; AMOssy, 20I4). Definida entonces como un tipo de intercambio poco susceptible de llevar a un acuerdo, la polémica es detectable, desde el punto de vista lingüístico y retórico, por sus marcas de oposición, inclusive por sus formas de violencia verbal (injurias, insultos, vituperio, sarcasmo) que tienden a enfatizar los antagonismos. Esta forma verbal es poco compatible con el uso de argumentos que puedan dar lugar a la discusión ${ }^{5}$.

Así, los panfletos, analizados por Angenot como típicos de la postura polémica, tienden a presentar la o las posiciones adversas bajo una forma ya condenada, mediante una retórica asertiva y fuertemente modalizada (ANGENOT, 1982). Es cierto que es posible identificar en ese tipo de escritos una dimensión argumentativa (AmOssY, 2008:4), en el sentido de que los panfletarios, por la expresión verbal de sus juicios y emociones, apuntan indudablemente a orientar axiológicamente la representación que los lectores se forman del enunciador y de su blanco. Pero se trata propiamente de una estructura argumentativa: los panfletarios solo explicitan

5] Aquí entendemos que un «argumento» es un «enunciado (o fragmento de discurso) verosímil que expresa una razón avanzada para acreditar una proposición controvertida, con el estatus de conclusión» (PLANTIN, 2002: 65). 
marginalmente las razones de su disenso y no se esfuerzan por crear un espacio común de intercambio agonístico con su(s) adversario(s).

Actualmente, cuando en ciencias humanas y sociales nos interesamos en el término "controversia» encontramos algunas características que remiten a la vez al debate y a la polémica, lo que nos permite distinguir al menos dos propiedades específicas de este término. La controversia, al igual que la polémica, designa una confrontación discursiva polarizada, es decir, a la vez focalizada en un objeto preciso y capaz de suscitar oposiciones tajantes (CHARAUDEAU, 20I5:I5). Esa doble dimensión, como hemos señalado, no es necesariamente definitoria de un debate. La controversia aparece entonces como una subcategoría de la forma debate, con la cual comparte las propiedades generales, con la cualidad específica de ser polarizada. Pero se distingue también de la polémica por el hecho de que la polarización es, de ambas partes, objeto de una argumentación exhaustiva. En la mayoría de los trabajos, describir una controversia, sea esta religiosa, estética, científica, literaria, filosófica, sociotécnica o política, implica hacer referencia a un complejo de argumentos contrapuestos.

Desde el punto de vista de las disciplinas del discurso, es precisamente esta articulación entre una fuerte polarización y una fuerte estructura argumentativa lo que distingue la controversia de otros intercambios agonísticos: si la polarización entre los protagonistas disminuye, la controversia puede convertirse en una «discusión», una «deliberación», un «diálogo»; si, aun encendida, la polarización deja sin embargo de apoyarse en la formulación explícita de argumentos para volcarse más bien hacia procedimientos de descalificación del adversario, entramos en la "querella», la «disputa», la "contienda», o, justamente, la "polémica». Algunos investigadores ponen en relación esa oposición en el uso de los términos con su origen: mientras «controversia» en latín está ligado a la lengua del tribunal, en el sentido de oposición regulada por el aparato judicial (DESBORDEs, 1995), polemos, en griego, designa la guerra: esa connotación belicosa sobrevive en el adjetivo y en el sustantivo derivados. Encontramos esta distinción en la caracterización de la controversia como debate «regulado» (DASCAL, I995, 2008; AMOSSY Y BURGER, 20II) distinguible de otras formas de intercambio polémico que consisten, por el contrario, en transgredir — aunque más no sea de manera codificada y previsible- las normas formales del razonamiento, del lenguaje civilizado y del respeto al adversario. Esos diferentes registros discursivos pueden, evidentemente, sucederse dentro de un mismo debate concreto y la denominación de un intercambio 
agonístico por parte de los propios protagonistas puede oscilar entre diferentes términos: acusar al adversario de transformar una controversia en polémica es una estrategia común de descalificación de sus tomas de posición ${ }^{6}$.

Confrontación discursiva argumentada y polarizada, la controversia es también considerada, en la mayor parte de los trabajos sobre el tema, como una confrontación «prolongada», «durable», «reiterable», «reciclable» y «resistente» (BENOIT-BARNÉ Y MCDONALD, 2OII; DASCAL, I995, 2008; EEMEREN Y GARSSEN, 2008; LE ROBERT, 200I; RENNES, 2007a). Mientras que un debate, una discusión, un desacuerdo, una disputa, una polémica, un litigio o una deliberación pueden limitarse a una sola ocurrencia, hablar de una controversia es hacer referencia a una serie de intercambios agonísticos que parecen tratar sobre una misma cuestión.

Esta dimensión continuada y reiterable de la controversia tiene múltiples implicancias para la investigación. En primer lugar, la temporalidad misma de la controversia puede volverse objeto de análisis: es posible interesarse, así, en su emergencia, su publicización, su dispersión en variadas arenas, sus fases de reflujo, de resurgimiento, eventualmente de cierre (LILTI, 2007). En segundo lugar, los propios argumentos de un debate concreto pueden abordarse en su temporalidad y su «trayectoria» en relación con las "pruebas» que atraviesan (CHATEAURAYNAUD, 20II) en la medida en que se confrontan sucesivamente con contraargumentos en otros debates concretos que forman parte de la misma controversia. En tercer lugar, a lo largo del trayecto de una controversia, algunos argumentos, que se terminan por considerar "típicos» de una controversia, son movilizados muchas veces por diferentes actores sociales en situaciones de enunciación diversas muy alejadas del contexto de elaboración de esos argumentos. Así, es conveniente que en una investigación sobre una controversia no se aplasten esos diferentes niveles de temporalidad: la de los protagonistas que participan y alimentan sucesivamente la controversia y la de las formas argumentativas que estos transmiten aunque ellos no las hayan elaborado, habitualmente de más larga duración (RENNES, 2OIIa).

Por último, esta dimensión continuada y reiterable de la controversia va de la mano con el carácter fuertemente metadiscursivo e interdiscursivo de los intercambios agonísticos que la constituyen: sus protagonistas tienden a inscribir aquello que los divide en una historia discursiva, refiriéndose, en cada debate, a otros debates

6] Esos «juicios de polemicidad» (JACQUIN, 2011) fueron destacados en numerosos debates. Ver, por ejemplo, CHATEAURAYNAUD Y TORNY (1999) y PLANTIN (2003). 
anteriores que presentan como si se trataran de la misma cuestión litigiosa (aborto, matrimonio de parejas del mismo sexo, pena de muerte, biotecnologías...). A la inversa, raramente es categorizado de entrada como una controversia un debate en el cual lo que está en juego y el objeto parecen enteramente inéditos a los actores. En suma, en una investigación, el hecho de que los propios protagonistas de un debate lo caractericen como uno que reactualiza una cuestión polémica (clivante) ya debatida anteriormente puede formar parte de los criterios — necesarios, pero no suficientes - que permiten calificar su intercambio como una "controversia».

Además de su carácter polarizado, argumentado y reiterable, la controversia remite también, en las ciencias humanas y sociales, a intercambios agonísticos que tienen una dimensión "pública». Esta publicidad remite aquí a una característica al mismo tiempo morfológica (discursiva) y situacional: en el plano discursivo, la "gramática pública» designa una restricción argumentativa, la que hemos mencionado a propósito de un debate y que consiste, para los debatidores, en enunciar razones para actuar, adherir o rechazar que, lejos de limitarse solo a la expresión de sus sensaciones o de su interés singular, deben ser objeto de una operación de desingularización. En el plano situacional, la publicidad refiere a la existencia de un auditorio potencialmente indeterminado: contrariamente a un intercambio agonístico que se desarrolla exclusivamente en un espacio interaccional y perceptual en el que los miembros controlan las fronteras (por ejemplo un desacuerdo entre cercanos que tiene lugar en la cocina de un departamento privado), tendemos a calificar de controversia a un debate reiterado en diversas situaciones de comunicación en las cuales los protagonistas no tienen siempre «control sobre quiénes podrían observarlos y no tienen medio de seleccionar el auditorio al que se dirigen», según la definición de «situación pública» que propone Joseph Gusfield (GUSFIELD, [I98I] 2009: 197).

Lejos de ser una propiedad fija, la publicidad designa también un proceso que puede reconocer diferentes grados de extensión (CARDON, HEURTIN Y LEMIEUX, I995): una comunicación científica en un coloquio, una intervención militante en un espacio asociativo no tienen, evidentemente, un auditorio tan indeterminado, diversificado y extendido como una toma de palabra parlamentaria retransmitida por los grandes medios, pero no por ello dejan de constituir, en grados diversos, situaciones de comunicación pública en el sentido en que lo entiende la sociología de las interacciones.

Luego de este primer examen de los usos del término "controversia» en las ciencias humanas y sociales, podemos definir la controversia como una confrontación discursiva polarizada, argumentada, reiterada y pública. Sin embargo, esa 
base definicional abarca todavía una gran diversidad empírica de debates desde el punto de vista de su duración, su perímetro, su grado de publicidad, su situación de enunciación, sus protagonistas, sus objetos. Una confrontación argumentada y reiterada, que trata sobre la interpretación de un acontecimiento, de un precepto religioso, de una teoría, de una doctrina, de una obra de arte que, sin estar confinada a un espacio "privado", se desarrolla sin embargo en el seno de un grupo de «pares» en una institución científica, artística, literaria, eclesiástica, y que se extingue al cabo de algunos meses, puede definitivamente entrar en la definición enunciada más arriba de «controversia». Pero sucede lo mismo con un debate de varias décadas suscitado por una reivindicación que transforma fundamentalmente una norma estatal-nacional relativa a la filiación, a la fiscalidad o a la libertad de circulación, que se despliega en una multiplicidad de arenas (Parlamento, gobierno, prensa, universidad, asociaciones) y que, a lo largo de su trayectoria, implica a diferentes generaciones de debatidores, los cuales «relanzan» sucesivamente una cuestión polémica que ellos no iniciaron. Para mejorar la comparabilidad de la conflictividad social que se teje en los diferentes debates empíricos sin aplanar la singularidad de cada uno de ellos, no solo es útil distinguir diferentes formas agonísticas conexas a la controversia sino también diferentes formas de controversias según sus contextos de emergencia, sus objetos, sus actores y sus públicos.

\section{II. ¿CONFRONTACIONES POLÍTICAS AGONÍSTICAS INSTITUCIONALIZADAS?}

Las cuestiones polémicas enumeradas al inicio de este artículo refieren a la instauración, la modificación o la supresión de una medida relativa a una colectividad, sea que esa medida remita al engendramiento, la salud pública, la repartición de la riqueza, la seguridad, las uniones matrimoniales o los derechos civiles. Propongo calificar como "políticos» a esos debates que exhiben una confrontación pública de, por un lado, juicios que ponderan una situación o una proposición como contraria a un principio de justicia o al interés general, y, por otro lado, juicios inversos sobre la misma proposición o situación; confrontación discursiva que tiene como apuesta principal el mantenimiento o la supresión de la situación o del proyecto que es objeto de controversia. Dicho de otra manera, la dimensión política de una controversia no está vinculada a ciertos objetos de debate que serían de naturaleza política; es el punto de llegada de un proceso por el cual los actores 
publicitan una situación o una proposición como un problema de (in)justicia o de interés general. Esa publicización puede contribuir a su vez a la politización de nuevos espacios y de nuevos actores: cuando una cuestión polémica adquiere una publicidad creciente vía su reiteración en diversas arenas, el propio requerimiento de tener una opinión sobre ese clivaje tiende a imponerse de forma creciente en situaciones de comunicación de lo más diversas, sea en conversaciones de café, en almuerzos familiares o en una entrevista en los medios ${ }^{7}$.

A partir de los trabajos de Jürgen Habermas y de las investigaciones históricas realizadas en esa línea, existe un acuerdo acerca de la relación entre el desarrollo de la expresión pública de opiniones de disenso sobre cuestiones políticas, estéticas o filosóficas en las sociedades alemana, francesa e inglesa del siglo xviII y la creciente organización social de una burguesía letrada surgida en el seno de espacios de sociabilidad marcados por la circulación de la imprenta: cafés, sociedades de especialistas, salones, clubes (HABERMAs, [1962] 1978) ${ }^{8}$. No obstante, es en el curso del último tercio del siglo xIx que se desarrolla, en las sociedades industriales occidentales, un nuevo tipo de controversias políticas que llegan a un público potencial compuesto por el conjunto de los miembros de la nación y que se inscriben en formas organizadas de expresión colectiva de los disensos.

Esta institucionalización de ciertas formas de controversias políticas y la ampliación de sus públicos se deben sobre todo al desarrollo de la escolarización primaria y de la prensa masiva. Ese doble proceso no significa solamente el aumento considerable del público lector; también favorece la constitución, dentro de las poblaciones nacional-estatales, de una cultura política común, incluso de una definición común de los problemas públicos y de las cuestiones polémicas a escala nacional ${ }^{9}$. Estas últimas, a menudo formuladas en la prensa de forma binaria (solo se puede estar a favor o en contra de tal o cual medida) participan de una espectacularización de lo político bajo la forma de un duelo entre posiciones

7] Sobre el rol de las cuestiones polémicas en los procesos de politización en interacciones ordinarias, ver DUCHESNE Y HAEGEL (2003).

8] Entre las investigaciones históricas que se apoyan en el trabajo de Habermas poniendo algunos puntos en discusión, consultar sobre todo DARNTON (1991) y CHARTIER (1991) para el siglo XVIII francés; sobre las fronteras de la esfera pública burguesa y las modalidades de la palabra pública contestataria en la misma época, ver, entre otros, FARGE (1992).

9] Sobre las condiciones materiales de la constitución de culturas políticas nacionales a partir del último tercio del siglo XIX, ver por ejemplo CHARLE (2011). 
antagonistas ${ }^{10}$. Esa espectacularización del disenso que se desarrolla a lo largo del siglo xx, la cual se supone destinada a hacer más cautivantes los temas sociopolíticos para un público socialmente heterogéneo, se debe también a la profesionalización del periodismo y a la ideología que la acompaña: el hecho de dar a leer y a ver posturas opuestas poniéndolas en pie de igualdad conforma una puesta en escena de la neutralidad y de la objetividad periodísticas, erigidas en criterio normativo del buen ejercicio de la profesión.

No se trata de reducir las controversias políticas a una invención mediática vinculada al desarrollo de la prensa comercial de masas y a la alfabetización de la población: sea que refieran al derecho de las mujeres de la instrucción pública, a la construcción de la Torre Eiffel, al maltrato de animales domésticos o a la prohibición de la corrida, las controversias políticas que ocupan la prensa francesa de los años I880 se relacionan con organizaciones y movilizaciones colectivas. Ellas se benefician de la institucionalización de las formas de expresión pública directa e indirecta de las opiniones, se trate de la legislación que garantiza la libertad de prensa, del derecho a la huelga y la manifestación o, para los hombres franceses mayores, del derecho al voto. Incluso si esas herramientas de expresión directa e indirecta de las opiniones, fruto de luchas sociales y de compromisos políticos, son ellas mismos objeto de restricciones y de contraofensivas que debilitan su uso, contribuyen a la formación y a la publicidad de clivajes y disensos que atraviesan a la población.

La institucionalización de la expresión pública de los antagonismos, precisamente porque está organizada, controlada y regulada, no produce, en las sociedades que garantizan esos derechos, una proliferación del debate público a todos los niveles: ciertas normas y valores sacralizados, ciertas decisiones gubernamentales tomadas en contextos de crisis, de guerra o de «estado de emergencia» son sustraídas de la discusión pública; ciertas corporaciones profesionales y ciertas instituciones, por ejemplo las que representan la «neutralidad del Estado», se mantienen al margen de la politización; finalmente, y sobre todo, ciertos grupos sociales no llegan, por falta de legitimidad o de recursos, a hacer escuchar su voz. Dicho de otro modo, desde el punto de vista de una sociología de la participación, no alcanza con enunciar que la existencia de intercambios agonísticos públicos es una marca del carácter democrático de una sociedad (AMOSSY, 20I4) sino que conviene interrogar

10] Sobre la configuración de los debates públicos en la prensa francesa de los años 1880 ver, por ejemplo, ANGENOT (1989, cap. 31). 
concretamente la naturaleza y el perímetro de las cuestiones que acceden al rango de objeto de debate público, las arenas involucradas por ese proceso de politización y el estatus de los y las participantes. Desde una perspectiva de teoría política, de la que la sociología y el análisis del discurso pueden nutrirse, la filósofa Chantal Mouffe expresa una idea análoga cuando pone en relación la democratización de una sociedad con la ampliación de los temas de debate, de los tipos de actores y actoras y de las arenas de confrontación agonística (MOUFFe, I994).

\section{CONTROVERSIA POLÍTICA, CONTROVERSIA CIENTÍFICA}

En las controversias públicas que refieren a cuestiones políticas polémicas, son, como vimos, principalmente los valores de lo justo y del interés común —y sus reversos denunciantes: lo injusto, lo inútil y lo dañino- los que son movilizados por cada una de las partes que se oponen. Desde el punto de vista de su axiología, también podríamos distinguir este tipo de controversias de aquellas en las que los protagonistas se apoyan más bien en valores estéticos (en las que se discute por ejemplo la calificación de una obra artística como obra maestra o como impostura) o en valores de verdad (en las que se discute por ejemplo la existencia o la interpretación de un fenómeno dado). En la práctica, esas axiologías pueden ser sucesivamente empleadas en una misma controversia. Los valores invocados para oponerse a la construcción de una obra monumental en un espacio urbano pueden ser sucesivamente políticos o estéticos. En cuanto a las controversias ambientales o bioéticas, los desacuerdos que las caracterizan pueden remitir simultáneamente a núcleos políticos, científicos o técnicos. Esa hibridez se ha vuelto en sí misma objeto de una importante corriente de investigación en el cruce entre la sociología de la ciencia y de las movilizaciones (PESTRE, 2007: 38-42; BARTHE Y BORRAZ, 2OII).

Incluso en controversias políticas cuyos temas no parecen tener ninguna relación con los resultados de una investigación científica se producen a menudo disensos que aluden a la verdad o la falsedad de saberes movilizados por los debatidores para sostener sus tomas de posición: a fines del siglo XIX y principios del xx, los estudios sobre las diferencias entre el cerebro masculino y el femenino se vuelven tema de debate entre feministas y antifeministas que se enfrentan en torno al acceso de las mujeres a la abogacía (RENNES 2007a: I65-190). Un siglo más tarde, investigaciones en ciencias sociales y teorías psicoanalíticas sobre el género, la se- 
xualidad y la familia son invocadas en las controversias sobre la unión y la filiación de parejas del mismo sexo (stambolis-Ruhstorfer, 20I5). Así, los desacuerdos propiamente científicos, es decir, aquellos que refieren a saberes no estabilizados (LATOUR, I989) y los desacuerdos propiamente políticos, es decir aquellos que ponen en juego la definición de normas sociales, pueden corresponder a diferentes fases o dimensiones de una misma controversia.

Es posible también distinguir las controversias según las arenas en las que se despliegan y el tipo de actores y actoras que se involucran. Desde este punto de vista, según la definición propuesta por Dominique Raynaud, que se hace eco de numerosas investigaciones en sociología de la ciencia, una controversia científica es una "división persistente y pública dentro de una comunidad científica cuyos miembros, aliados o no, sostienen argumentos contradictorios en torno a la interpretación de un fenómeno dado» (RAYNAUd, 2003: 8). En un artículo que desde entonces es una referencia sobre el tema, Cyril Lemieux propone una definición de la controversia en general que no está tan alejada de la definición de la controversia científica:

«Dentro de la ‘familia〉 de los conflictos triádicos (i.e. compuestos por dos partes en conflicto y por el público), las controversias parecen distinguirse claramente por la composición extremadamente selectiva del público que movilizan (...). Pero, en cambio, basta con que el público solicitado se amplíe hacia el ‘gran público〉 —en otras palabras, hacia los profanos y los no especialistas - para que la controversia [tienda] a mutar en lo que estaríamos tentados de ver como una «crisis institucional»» (LEMIEUX, 2007: 196).

Una controversia es, en suma, «un conflicto tríadico en el cual el único juez es el público de pares», lo que implica, precisa Lemieux, espacios sociales autónomos en los que los agentes desarrollen «competencias distintivas de juicio que les permitirán reconocerse mutuamente como parte de un público de pares en oposición a la masa de profanos» (LemieuX, 2007: 196).

Esta definición de la controversia, que pone en el centro el estatus de los actores que participan de ella, es heurísticamente útil para describir el desarrollo de debates que quedan confinados, así como las fases de confinamiento de ciertos debates. Múltiples controversias científicas, religiosas, estéticas y literarias pueden en efecto describirse a partir de una definición de ese tipo desde el momento en que lo que 
ponen en juego, en el plano cognitivo o epistemológico, no es significativo, ni siquiera conocido, más allá de la comunidad de especialistas en la cual emergieron, ni retraducido en términos de justicia, de interés general o de acción pública.

Ahora bien, es necesario tener presente que tal distinción entre pares y profanos es en sí misma susceptible de ser renegociada y de constituir a su vez un tema de disputa (CALlON, 198I). Asimismo, las controversias confinadas solo pueden servir parcialmente de modelo cuando se constituye un corpus para investigar los intercambios agonísticos que refieren a cuestiones políticas polémicas. De hecho, por un lado, las controversias políticas no tienen lugar principalmente dentro de una esfera autonomizada de producción de saber, ni siquiera dentro de una esfera autonomizada de producción de la decisión pública; por otro lado, sus enunciadores no se definen exclusivamente a partir del distingo entre especialistas y profanos. Ciertamente, en las controversias políticas, aquellos y aquellas que Becker llama los «emprendedores morales» (BECKER, [1963] I985: I7I y siguientes) pueden erigirse en especialistas de normas sociales a promover o defender. Al igual que los expertos involucrados en debates políticos polémicos, estos emprendedores morales pueden buscar distinguirse de los profanos mediante una forma de experticia, incluso si esta no alude a hechos científicamente conocidos y validables por los pares sino a la normatividad social.

Sin embargo, incluso tomando en consideración a esos emprendedores morales, la oposición experto/profano dista de organizar totalmente el derecho de acceso a las controversias políticas. Algunos individuos pueden participar en ellas en tanto «víctimas» o «beneficiarios» potenciales del proyecto o de la situación en debate o incluso como simples ciudadanos afectados por las cuestiones de justicia o de interés común que la controversia levanta. Ahora bien, este tipo de configuración —un debate sobre una cuestión política polémica que involucra una pluralidad de arenas y de protagonistas que no se categorizan exclusivamente en torno a la oposición experto/profano- tiende evidentemente a ser descrita, en múltiples trabajos de ciencias sociales, como una "controversia» en la medida en que los desacuerdos son argumentados, publicitados, polarizados y duraderos ${ }^{11}$.

11] Entre los trabajos sobre cuestiones políticas polémicas que emplean el término controversia como categoría de análisis, ver por ejemplo PHILLIPS (1999), TERZI Y BOVET (2005), LABORDE (2008), SMADJA (2012) JULLIARD Y CERVULLE (2013) y CHARAUDEAU (2015) así como las múltiples lecciones sobre el análisis de controversias a partir de los estudios de sociología, de ciencia política, las escuelas de periodismo, de ciencias de la información y de comunicación. Sobre este punto, consultar, por ejemplo, BADOUARD (2015). 


\section{POLITIZACIÓN Y DISPERSIÓN: CONFORMAR MATERIALES DE INVESTIGACIÓN}

Si admitimos que toda politización es acompañada por una dispersión de las arenas y de los actores que toman posición sobre la cuestión polémica, analizar una controversia política implica distanciarse de un consejo que habitualmente se les da a los y las estudiantes que intentan constituir un corpus de posiciones antagonistas sobre una cuestión política: para comparar tomas de posición, sería conveniente que estén representadas por subcorpus de tamaño similar e inscriptos en una misma situación de comunicación o un mismo género discursivo, tales como un foro de discusión, una asamblea deliberativa o incluso periódicos nacionales.

Esta precaución metodológica es en parte fundada: es útil para comparar regularidades lexicales o sintácticas de los diferentes subcorpus (por ejemplo, mediante enfoques textométricos) y para interpretar las diferencias entre esos subcorpus. En la medida en que estos subcorpus pertenecen a un mismo marco genérico y situacional, las fronteras que organizan lo decible y lo indecible, las reglas tácitas o explícitas que enmarcan las formas de expresión y por lo tanto la formulación de los desacuerdos tienden a ser compartidos por los enunciadores. Con esta precaución metodológica, ciertamente, existe menos riesgo de confundir aquello que remite a diferencias de posicionamiento político entre los protagonistas del conflicto y aquello que se debe al hecho de que, en situaciones de comunicación distintas, los enunciadores expresan su punto de vista de modo diferente.

Sin embargo, respetar estrictamente esta consigna metodológica no permite interrogar el proceso de politización de una controversia. En efecto, dicha posición metodológica conduce a restringir la proliferación de tomas de posición a tal o cual arena de debate público o a tal o cual género discursivo. Asimismo, esta consigna crea un artefacto que consiste en presentar como equivalentes cuantitativamente posiciones que, en el espacio social, son asimétricas en cuanto a su visibilidad, su tiraje o su difusión.

En efecto, a lo largo del proceso de politización de una controversia, no solo las diferentes posiciones se expresan potencialmente en el conjunto de las esferas de la actividad social, sino que, además, los partidarios y los adversarios de la medida controvertida pocas veces se expresan en las mismas situaciones de enunciación ni en partes iguales. Así, los polemistas que sostienen las reivindicaciones políticas más heterodoxas tienen generalmente menos probabilidad que aquellos cuyas tomas de posición coinciden con la definición hegemónica de la realidad social de que sus posiciones sean transmitidas al gobierno, al Parlamento, a los discur- 
sos informativos de los medios dominantes o a las publicaciones de los grandes editores. Los «heterodoxos» tendrán entonces más acceso a soportes editoriales y de difusión de sus ideas creados por ellos mismos y a modalidades de enunciación colectiva y/o anónima (folleto, eslogan, petición, carta abierta, mural). De hecho, mucho antes del uso de internet como herramienta de comunicación militante, la historia de las confrontaciones sobre cuestiones políticamente polémicas es inseparable de la creación, al margen de los medios dominantes, de soportes de expresión y de difusión de las ideas contestatarias, ya fuera de forma verbal, icónica o audiovisual, oral o escrita ${ }^{12}$.

Así, a lo largo de la controversia sobre el acceso de las mujeres a las profesiones tradicionalmente masculinas que se desarrolla entre los ańos I870 y 1930 en Francia, las feministas, para expresar públicamente sus posiciones, crean asociaciones, órganos de prensa a favor del derecho de las mujeres y editan panfletos específicamente dedicados a su causa. Una gran parte de sus adversarios, que comienzan a llamarse, a fines del siglo XIX, «antifeministas» $\mathrm{O}$ «masculinistas», intervienen por el contrario en los grandes periódicos, publican ensayos en las principales editoriales parisinas y tienen aliados que defienden su causa en lugares de poder político y académico sin necesidad de constituir órganos específicos de ideas antifeministas (RENNES, 2007a: 9-I5). Solo en una sociedad donde el «masculinismo» ya no es decible en los medios dominantes y en las instancias de poder es posible que este se vuelva una causa específica con sus asociaciones, sus periódicos, sus editoriales. En cambio, si pretendemos constituir un corpus que permita dar cuenta de la controversia de los años I870-1930 sobre el derecho de las mujeres, sería en vano buscar una simetría de géneros discursivos movilizados por las dos partes (por ejemplo, dos periódicos militantes antagonistas que ocuparan una posición homóloga en el campo periodístico) o un espacio común en el que esas dos partes pudiera expresarse de manera equivalente (por ejemplo, un gran periódico nacional).

En una investigación sobre una controversia política, el seguimiento minucioso de las menciones del discurso adversario en el seno de cada posición dibuja por el contrario los contornos de un espacio enunciativo agonístico fundamentalmente asimétrico y heterogéneo (desde el punto de vista de la situación de enunciación y del «tamaño» de los diferentes protagonistas) y no sincronizado (desde el punto de

12] Sobre la historia del «mediactivismo» a partir de los años 1960, ver CARDON Y GRANJON ([2010] 2014). 
vista de la temporalidad de los enfrentamientos). De ese modo, en la controversia que acabo de mencionar, algunos parlamentarios denuncian, en una sesión pública, una serie de artículos aparecidos varias semanas antes en un pequeño periódico feminista, mientras que militantes a favor del derecho de las mujeres organizan una acción colectiva delante de un teatro en el que se realiza una comedia cuyo principal argumento narrativo expresa una posición hostil al acceso de las mujeres a las profesiones tradicionalmente masculinas (RENNES, 2007: 107-I27). Entre los adversarios de las reivindicaciones feministas, las propias formas de intervención agonísticas son muy heterogéneas y en gran parte dependientes de los recursos estatutarios y socioeconómicos de los actores movilizados. Así, los médicos y los abogados producen argumentarios en la prensa masiva, y por intermedio de sus aliados, en el Parlamento y en el consejo municipal, para apoyar o, más comúnmente, para denunciar las demandas de apertura de sus respectivas corporaciones a las mujeres. Logran así transformar en cuestión de justicia y de interés general sus desacuerdos internos sobre el carácter mixto de la abogacía y de la medicina. En cambio, otras profesiones, como los choferes, también en su mayoría hostiles a que las mujeres ejerzan su oficio, no disponen de los mismos recursos para transformar sus problemas corporativos — la llegada de las primeras mujeres choferes- en controversia pública: es necesario, entonces, consultar la prensa sindical de los choferes, así como los archivos policiales y judiciales en los que se enumeran los accidentes malintencionados que algunos provocan contra las nueva conductoras para captar indicios de protesta contra la llegada de las mujeres (RENNES, 20I6).

Como puede verse en los ejemplos, que nos confrontan con el límite entre controversia pública y conflicto social, tomar en consideración la dispersión, la heterogeneidad y las formas asimétricas de las intervenciones agonísticas nos lleva a explorar la dimensión multimodal de estas últimas y, por lo tanto, a interrogar las articulaciones posibles entre el análisis de las controversias públicas y la sociología de los conflictos sociales y de la acción colectiva. Numerosas acciones colectivas son reconocidas como una causa, fracasan o se debilitan sin que se desarrolle ninguna controversia pública en relación con el objeto de la reivindicación: en ese sentido, las investigaciones sobre movilizaciones pueden prescindir de las herramientas del análisis de controversias. Lo recíproco no se corrobora: una controversia sobre una cuestión política polémica difícilmente pueda perdurar sin actores aliados y sin un continuum de intervenciones agonísticas que no se reducen únicamente a la producción de argumentarios verbales. Por ejemplo, las controversias políticas 
alrededor de los derechos de minorías sexuales y de la enseñanza de una nueva pedagogía sobre la igualdad de género en la escuela, que se desarrollaron en muchos países europeos a fines del siglo xx e inicios del xxI, se inscriben en un marco más amplio de movilizaciones y contramovilizaciones. Éstas incluyen técnicas de protesta colectivamente organizadas (ocupación, manifestación, utilización «retórica» de prácticas corporales) ${ }^{13}$ que poseen, según sus iniciadores, una dimensión argumentativa y no solo expresiva (RENNES, 20IIa: I52-I6I).

No obstante, estudiar el proceso por el cual elementos del discurso adverso son retomados, reformulados y refutados de forma multimodal por actores heterogéneos conlleva el riesgo de confrontarse, a lo largo de la investigación, a corpus potencialmente ilimitados. Por ello, no parece factible adoptar la interdiscursividad — abordada, además, desde una perspectiva multimodal— como único criterio de selección de los materiales de análisis.

Otros criterios de delimitación son, de hecho, compatibles con el estudio de la dispersión y de la politización. Por ejemplo, puede ser pertinente seguir, en una diversidad de arenas, la circulación interdiscursiva de una sola fórmula o de un tipo de argumento particular ${ }^{14}$; también es posible concentrarse en la interdiscursividad que se despliega dentro de un solo episodio o de un acontecimiento circunscripto de la controversia. Se evita así verse confrontado a una masa incontrolable de materiales sin por ello delimitar a priori los corpus en términos de género discursivo o de situación de comunicación.

Además, trabajar sobre la diseminación y la politización de una controversia no implica renunciar a la posibilidad de incluir subcorpus delimitados según criterios genéricos o comunicacionales. El estudio exhaustivo de un subcorpus, compuesto por ejemplo por un conjunto de debates parlamentarios sobre la cuestión polémica, permite objetivar no solamente las asimetrías entre las diferentes posiciones dentro de instituciones discursivas estratégicas sino también, si el corpus está constituido por subpartes cronológicas, la evolución de esa relación de fuerzas. Sin embargo, un corpus como ese no debería ser considerado suficiente para analizar el proceso de politización y por lo tanto de dispersión que caracteriza a las controversias políticas.

13] El uso del cuerpo — desnudo, atado, amordazado, disfrazado o enmascarado— como metáfora de un abuso de poder o de una injusticia es muy estudiado desde la perspectiva de la «retórica de los movimientos sociales». Ver por ejemplo DELUCA (1999).

14] Sobre este tipo de investigaciones ver EBEL Y FIALA (1983) y KRIEG-PLANQUE (2009). 


\section{CASO, PROBLEMA PÚBLICO}

Tal como ha sido presentada hasta aquí, la politización de una cuestión polémica implica una cierta cantidad de características comunes a los procesos de desarrollo de un "caso" (affaire), analizado en particular por Elisabeth Claverie. Tal como ella lo concibe, el concepto de caso debe ser pensado en relación con el cotilleo y al escándalo al mismo tiempo (CLAVERIE, I994 y 1998). Si un individuo o un colectivo transgrede valores que se supone debe honrar - sea en el marco de actividades políticas, profesionales, financieras, familiares- y si esa transgresión es conocida por una cantidad limitada de personas, puede restringirse a suscitar un simple "chusmerío» dentro de una red de conocidos. Si la revelación de tal transgresión se amplía más allá de esa red y lleva a una desaprobación pública de la conducta transgresora, se convierte en un «escándalo» (DAMPIERRE, I954; THOMPSON, 2000; BLIC Y LEMIEUX, 2005).

En consecuencia, si algunas personas públicamente repudian esa desaprobación, al defender al individuo o al colectivo acusado contra sus acusadores al punto de que se genera un clivaje público en torno a la inocencia o la culpabilidad del acusado, nos encontramos frente a un "caso». Así, en Francia, en el caso Dreyfus en I894 o Strauss-Kahn en 20II, un clivaje duradero se cristaliza en torno a la calificación de los actos incriminados y en torno a la atribución de las posiciones de culpable o de víctima ${ }^{15}$. Como sucede en la constitución de una controversia política, la confrontación discursiva que se articula en torno a un caso es pública, argumentada y polarizada, y puede ser fuente de politización de las interacciones ordinarias.

Sin embargo, un caso solo se transforma en controversia bajo la doble condición de que se constituya, primero, en reivindicación política, despegada de la persona singular alrededor de la cual el caso se cristalizó, y, luego, que esa reivindicación suscite la formación duradera de dos campos antagónicos: por ejemplo, un caso de valores desemboca en una reivindicación sobre la legislación en materia sexual que se vuelve a su vez una cuestión polémica del debate público. Ese proceso de transformación de un caso en controversia política no es excepcional: en Francia, el debate sobre el «uso de velo» en las escuelas públicas surge inicialmente a partir del caso de tres chicas jóvenes y un director escolar en 1989, antes de volverse, durante

15] Esta distinción entre «escándalo» y «caso», que constituye una propuesta operativa para el análisis de la conflictividad pública, no describe los usos ordinarios de esos dos términos, habitualmente empleados como sinónimos. 
más de veinte años, una cuestión polémica problematizada como tema de acción pública autonomizada de los casos iniciales que acompañaron su emergencia.

Cien años antes, un proceso en cierto modo análogo se produjo en torno al acceso de las mujeres a la profesión de abogadas: encarnado al principio por un caso preciso - «el caso Jeanne Chauvin», en referencia al nombre de la primera egresada de derecho que se postuló al colegio de abogados de París en I897-, la cuestión del carácter mixto de la abogacía se vuelve, entre I898 y 1900, un debate nacional polémico que se despliega, al mismo tiempo, en el Colegio de abogados, en los grandes periódicos, en ensayos, en el teatro de comedia, en ficciones, en canciones, en la totalidad de la cultura visual y hasta en la cámara de diputados y de senadores donde finalmente se vota una ley que autoriza a las mujeres a estudiar abogacía (RENNES, 2007a).

De ese modo, las formas «caso» $\mathrm{y}$ «controversia» pueden corresponder a diferentes momentos en el trayecto de una cuestión polémica o a diferentes dimensiones de esta cuestión. Pero no todos los casos se transforman en controversias, así como no todas las controversias políticas se despliegan a partir de casos previos: una propuesta legislativa, una acción colectiva, la toma de posición de una personalidad pública con acceso rutinario a los grandes medios, la publicidad de una situación problemática por un «lanzador de alerta» sin notoriedad (CHATEAURAYNAUd Y TORNY, 1999) pueden contribuir a la emergencia de una controversia sin que previamente haya habido un caso localizado y personalizado.

El hecho de que una controversia política, a diferencia de un caso, se trate directamente de un problema de acción pública puede acercarla al «problema público» tal como lo aborda la sociología política. La constitución de un problema público está marcada, también, por el disenso: estos están presentes a partir del momento en que una situación se presenta como «anormal» y se figura la necesidad de intervención de un actor público (MUller y SUREL, 2000: 57). Por ejemplo, la identificación de las causas y las consecuencias del problema, la categorización de sus responsables y sus víctimas, la manera de ponerle fin y la identificación de los actores legítimos para hacerlo son la oportunidad de encuadres y contraencuadres (BENFORD y HUNT, [2000] 200I; GUSFIELD, [1989] 2012). Sin embargo, en una controversia política, el disenso se constituye antes de la puesta en intriga de una situación definida como problemática. Este disenso es con respecto al carácter problemático mismo de dicha situación la cual es encuadrada como un problema por una de las partes de la controversia y como un hecho justo y necesario por la 
parte adversaria. Así, en las «controversias de igualdad» (RENNES, 2007b; 2007c; 20Irb), el hecho de que una categoría de la población (las mujeres, los menores, los extranjeros, los homosexuales) no tenga legalmente acceso a un recurso dado constituye para algunos un problema de justicia, mientras que para otros tal restricción se justifica por el interés general y por las supuestas diferencias esenciales entre los grupos diferenciados jurídicamente.

A lo largo del trayecto de una controversia y de la evolución de la relación de fuerzas entre los protagonistas, puede suceder que la posición que define la situación como problemática se vuelva hegemónica, mientras que la definición adversaria se convierte en ilegítima: la controversia se ha transformado, entonces, en un problema público. Así, a partir de la década de I980, la pedofilia ha sido problematizada cada vez más como una situación anormal que requiere medidas de parte de los poderes públicos. Surgen debates sobre las causas de esta práctica, la cantidad de víctimas, la jerarquía de las medidas necesarias para contenerla. A pesar de ello, esta cuestión, convertida en problema público, no opone partidarios y oponentes a la pedofilia, como pueden oponerse, en los años 2000-20I0, defensores y adversarios del matrimonio de parejas del mismo sexo, de la libertad de usar fular con significación religiosa en la escuela o de la legalización del cannabis. En efecto, el derecho de los adultos a tener relaciones sexuales con niños, decible y escuchable en la Francia de los años I970 (BERARD y SALLÉ, 2OI5), se volvió indefendible en el debate público a fines de los años I980 (BOUsSAguet, 2008). Lo que hubiera podido constituir una controversia durable sobre la autorización de relaciones sexuales entre adultos y niños se convirtió en un debate sobre los medios para luchar contra aquello que se definió, de forma dominante, como el problema de la pedofilia.

\section{LAS FRONTERAS DE LO DECIBLE EN PÚBLICO}

El ejemplo de la constitución de la pedofilia como problema público nos lleva nuevamente a un último aspecto que conviene explicitar: una controversia política implica el carácter públicamente decible de al menos dos puntos de vista opuestos. Dicho de otro modo, toda controversia política se despliega en el marco de un espacio dóxico que define una serie limitada de cuestiones debatibles cuya misma formulación acarrea una cierta cantidad de presupuestos que hace falta aceptar para involucrarse en el debate. 
Ese es el caso de las «controversias de igualdad» que comentaba más arriba: estas refieren al hecho de decidir si es justificable que el acceso legal a una institución (el derecho a casarse, a votar, a ejercer tal profesión, a concurrir a una competencia deportiva, a recibir una recompensa honorífica, a utilizar tal transporte público, etc.) quede reservado a una categoría dada de la población (los nacionales, los hombres, los titulares de tal diploma, las mujeres de tal edad, las parejas heterosexuales, las personas de tal estatura, tal religión, o tal color de piel) o si debe aplicarse a una categoría más vasta. Participar en este tipo de controversias implica ponerse de acuerdo en el hecho de que la institución, cuyo perímetro de acceso está en debate, constituye, en sí misma, un bien. De hecho, los y las que la denuncian como cómplice de un sistema que esperan sea abolido no pueden participar de la controversia en los términos en los que esta se plantea: si militamos a favor de la abolición del matrimonio, de la Legión de honor, de las «Grandes escuelas» o de los transportes contaminantes difícilmente nos involucremos en un debate sobre la ampliación de los beneficiarios de esos recursos.

Frente a esos polemistas que se ponen de acuerdo sobre los términos del debate, los y las que los rechazan están en la posición de lo que Jean-François Lyotard denomina el "diferendo» (LYOTARD, 1983: 25): su distancia social, política y/o cognitiva con respecto a los protagonistas del debate es tal que sus oposiciones no pueden enunciarse en un «idioma común». Cuando está en juego la instauración o la supresión de una medida relativa a una colectividad, las terceras posiciones, que tienden a poner en cuestión la alternativa en debate, se ven habitualmente marginadas en beneficio de la constitución de dos campos antagónicos: a favor y en contra. La polarización toma así la forma de una bipolarización, que es acompañada también por estrategias retóricas de «dicotomización» por las cuales cada uno de los campos subraya «la incompatibilidad de los dos polos», «lo fundamentado de la respuesta que él mismo ofrece» $\mathrm{y}$ «la inexistencia de toda otra alternativa» (DASCAL, 2008: 34).

Para comprender ese perímetro de lo debatible públicamente no alcanza con analizar lo que los adversarios que se enfrentan en una controversia tienen en común, en términos de sistema de valores y de elementos dóxicos (RENNES, 2007a: 369 y siguientes). También es conveniente interesarse en los actores, los objetos y las tomas de posición que quedan fuera de la controversia pública. En El orden del discurso, Michel Foucault identifica tres tipos de prohibiciones que organizan la producción del discurso y limitan su proliferación: los temas tabú («uno sabe que no tiene dere- 
cho a decirlo todo»), las «circunstancias» («no se puede hablar de todo en cualquier circunstancia») y el estatus del sujeto hablante («finalmente, no cualquiera puede hablar de cualquier cosa») (FOUCAULT, I97I: II-I2). Esta hipótesis general sobre las reglas de limitación de lo decible puede constituir un punto de partida para investigar sobre las formas de conflictividad discursiva autorizadas en una sociedad dada.

Un tema de investigación como ese supone no constituir corpus compuestos únicamente por discursos disponibles públicamente por haber sido ya publicitados por militantes, periodistas, editores, profesionales de la política. Los ensayos, los panfletos, los artículos de opinión en la prensa, los discursos gubernamentales y parlamentarios, los volantes, las peticiones, los manifiestos y, desde los ańos 2000, los sitios web son generalmente los primeros corpus hacia los que nos volcamos cuando nos interesamos en una controversia política. Ahora bien, los «contradiscursos», producidos por lo que Nancy Fraser denomina «contrapúblicos» que no pueden expresar sus ideas y dar forma a sus experiencias «dentro de los públicos dominantes» (FRASER, [I992] 200I: I38-I39), deben ser escrutados en materiales de investigación que no tienen tanta publicidad: archivos de asociaciones, policiales, judiciales o privados, entrevistas realizadas a activistas en el marco del trabajo de campo, observación etnográfica de espacios militantes cerrados en el que se producen intercambios metadiscursivos sobre lo que puede decirse y lo que debe callarse por fuera de esos espacios y donde se elaboran reivindicaciones antes de que estas se abran un camino hacia públicos más diversificados ${ }^{16}$. En definitiva, se trata de conformar materiales de investigación al margen de los discursos publicitados para aprehender aquellas tomas de posición que permanecen confinadas durante un tiempo determinado, o permanecen todavía por tiempo indeterminado, entre bastidores, en el backstage de la polémica pública.

16] Sobre la etnografía de los espacios militantes, ver sobre todo CEFAï et al. (2012). En cuanto al trayecto de las reivindicaciones desde los espacios militantes cerrados hacia públicos más amplios, este es objeto de la investigación colectiva desarrollada en el marco del seminario «Argumentar, revindicar, discutir» en la École des Hautes Études en Sciences Sociales: RENNES (2016). 


\section{CONCLUSIONES}

A partir de una exploración de los trabajos sobre los intercambios agonísticos y a partir de mis propias investigaciones he propuesto una distinción entre la controversia y formas emparentadas, especialmente el debate y la polémica; luego he precisado en qué consisten las fronteras y los solapamientos entre las controversias científicas y las políticas, y finalmente entre estas y esas otras formas de conflictividad política que son el «caso» y el "problema público». Al definir una controversia política como una confrontación argumentada, polarizada, dispersa en múltiples esferas de la actividad social y referida a una cuestión de acción pública, mi objetivo no es sustancializar la controversia política sino hacer comparables diferentes formas agonísticas y poder analizar la reiteración, la perpetuación y la politización de algunos debates: si llamamos "politización» al proceso por el cual una diversidad de actores, en una diversidad de esferas sociales, toma posición sobre una cuestión que divide a la sociedad, en nombre de un principio de justicia o de interés general, corremos el riesgo de perder la comprensión de ese proceso si lo restringimos de entrada al análisis de las arenas de debate más directamente vinculadas a la decisión pública, a los expertos y a los grandes medios.

Sea cual sea el área de acción pública en la que se inscriban las controversias, su análisis puede constituir una valiosa contribución a la sociología política y a las disciplinas del discurso. En primer lugar, el análisis de las controversias políticas permite esclarecer al mismo tiempo los conflictos de valores que atraviesan a una sociedad y el espacio dóxico común sobre el que se erigen los desacuerdos y las decisiones públicamente enunciables. En segundo lugar, el análisis de las controversias políticas, así como el de los casos y los problemas públicos, puede convertirse en una entrada en los procesos de politización en la medida en que las cuestiones polémicas se vuelven objeto de conversación y oportunidades para posicionarse dentro de interacciones ordinarias. Finalmente, trabajar sobre controversias políticas puede contribuir a destacar la historicidad de las políticas públicas, así como el estudio de las controversias científicas nos revela la historicidad del campo científico y de los saberes que allí se producen. En efecto, seguir el trayecto de una controversia científica o política que estuvo en el origen del desarrollo de conocimientos o de medidas de acción publica ahora legítimas nos lleva a captar, a la larga, la transformación de las relaciones de fuerza y los juegos de alianza que contribuyeron al establecimiento de nuevas orientaciones científicas o políticas. Sin embargo, la génesis conflictiva de las políticas públicas a menudo es ocultada 
no solo por el proceso ordinario de naturalización de las instituciones sin también porque aquellos que, desde instancias de poder, se opusieron a reivindicaciones ahora transformadas en leyes, en reglamentos, en derechos, tienen mucho interés en hacer olvidar su oposición tanto como las resistencias anteriores de aquellos de los que son herederos políticos.

Existen también múltiples razones para indagar en las controversias políticas, a condición de no olvidar que estas no son más que una parte de la conflictividad social: los grupos sociales tienen un poder desigual para transformar los problemas a los que se confrontan en controversia pública, y algunos de los clivajes que atraviesan el mundo social no son decibles en los términos del debate público. Existe, en los trabajos sobre controversias, una tensión en cuanto a la extensión del término: para algunos la controversia, vista desde el punto de vista de su trayectoria, engloba momentos de eclipse y de resurgimiento de visibilidad y de reflujos de publicidad; para otros la controversia es un momento específico en la historia de la confrontación en torno a una cuestión polémica, el momento en que las posiciones antagonistas logran enunciarse de forma durable en una diversidad de arenas públicas. No obstante, a los fines de esclarecer las fronteras de aquello que es políticamente debatible, poco importa que llamemos «controversia» a una fase particular del despliegue de una cuestión polémica o a la totalidad de su trayectoria. En ambos casos, es heurísticamente válido explorar no solo aquello que precede a la publicización de la controversia sino también sus márgenes: los tipos de problematización y las tomas de posición que ya no están, o que todavía no están, inscriptas en clivajes políticos percibidos como legítimos. 


\section{Referencias bibliográficas}

AMOSSY, RUTH (2008): «Argumentation et Analyse du discours: perspectives théoriques et découpages disciplinaires», en: Argumentation et Analyse du Discours, $\mathrm{n}^{\circ} 1$.

AMOSSY, RUTH (2014): Apologie de la polémique, París, PUF.

AMOSSY, RUTH Y BURGER, MARCEL (2011): «Introduction: la polémique médiatisée», en: Semen $n^{\circ}$ 31, pp. 7-24.

ANGENOT, MARC (1982): La Parole pamphlétaire, París, Payot.

ANGENOT, MARC (1989): 1889: un état du discours social, Longueil, Édition du Préambule.

ANGENOT, MARC (2012): «La notion d'arsenal argumentatif: l'inventivité rhétorique dans l'histoire», en: Frydman B. y Meyer M. (Dirs.), Chaïm Perelman (1912-2012), París, PUF, p. 39-68.

BADOUARD, ROMAIN (2015): «Enseigner les controverses en école de journalisme», en: Hermès, $n^{\circ}$ 73, p. 51-54.

BARTHE, YANNICK Y BORRAZ, OLIVIER (2011): «LeS controverses sociotechniques au prisme du Parlement», en: Quaderni, n 75, pp. 63-71.

BECKER, HOWARD ([1963] 1985): Outsiders, París, Métailié.

BENFORD, ROBERT Y HUNT, SCOTT ([2000] 2001): «Cadrages en conflit», en: Cefai D. y Trom D. (Dirs.), Les formes de l'action collective, París, Éditions de l'EHESS, pp. 163-194.

BENOIT-BARNÉ, CHANTAL Y MCDONALD, JAMES (2011): «L'évolution des pratiques rhétoriques de délibération publique par la controverse», en: Communication, vol. 28/2.

BERARD, JEAN Y SALLÉ, NICOLAS (2015): «Les âges du consentement. Militantisme gai et sexualité des mineurs en France et au Québec (1970-1980)», en: Clio, no 42, pp. 99-124.

BLIC, DAMIEN Y LEMIEUX, CYRIL (2005): «Le scandale comme épreuve. Éléments de sociologie pragmatique», en: Politix, no 71, pp. 9-38.

BOLTANSKI, LUC (1984): «La dénonciation», en: Actes de la recherche en sciences sociales, $\mathrm{n}^{\circ}$ 51, pp. 3-40.

BOUSSAGUET, LAURIE (2008): La Pédophilie, problème public, París, Dalloz.

CALLON, MICHEL (1981): «Pour une sociologie des controverses technologiques», en: Fundamenta Scientae, vol. 2, no 3/4, pp. 381-399.

CARDON, DOMINIQUE Y GRANJON, FABIEN ([2010] 2014): Médiactivistes, París, Presses de Science Po.

CARDON, DOMINIQUE, HEURTIN, JEAN-PHILIPPE Y LEMIEUX, CYRIL (1995): «Parler en public», en: Politix, n० 31, pp. 5-19.

CEFAI, DANIEL, CARREL, MARION, TALPIN, JULIEN, ELIASOPH, NINA Y LICHTERMAN, PAUL (Dirs.) (2012): Dossier «Ethnographies de la participation», en: Participations, n 4.

CHARAUDEAU, PATRICK (2015): La laïcité dans l'arène médiatique. Cartographie d'une controverse sociale, París, INA Éditions.

CHARLE, CHRISTOPHE (2011): Discordances des temps, París, Armand Colin.

CHARTIER, ROGER (1991): Les origines culturelles de la Révolution française, París, Seuil.

CHATEAURAYNAUD, FRANCIS (2011): "Sociologie argumentative et dynamique des controverses: l'exemple de l'argument climatique dans la relance de l'énergie nucléaire en Europe», en: $A$ contrario, no 16, pp. 131-150.

CHATEAURAYNAUD, FRANCIS Y TORNY, DIDIER (1999): Les Sombres Précurseurs. Une sociologie pragmatique de l'alerte et du risque, París, Éditions de l'EHESS.

CLAVERIE, ÉLISABETH (1994): «Procès, Affaire, Cause: Voltaire et l'innovation critique», en: Politix, $\mathrm{n}^{\circ}$ 26, pp. 76-85. 
CLAVERIE, ÉLISABETH (1998): «La naissance d'une forme politique: l'affaire du Chevalier de la Barre», en: Roussin, P. (Dir.), Critique et affaires de blasphème à l'époque des Lumières, París, Honoré Champion, pp. 185-260.

DAMPIERRE, ERIC DE (1954): «Thèmes pour l'étude du scandale», en: Annales ESC, vol. IX, n० 3 , pp. 328-336.

DARNTON, ROBERT (1991): Édition et sédition: I'univers de la littérature clandestine au XVIIIe siècle, París, Gallimard.

DASCAL MARCELO (2008): «Dichotomies and types of debates», en: In Eemeren F. H. van y Garssen B. (Dirs.), Controversy and Confrontation. Relating controversy analysis with argumentation theory, Amsterdam/Philadelphia, John Benjamins Publishing Company, pp. 27-50.

DASCAL, MARCELO (1995): "Observation sur la dynamique des controverses», en: Cahiers de linguistique française, $n^{\circ}$ 17, pp. 99-121. DESBORDES, FRANÇOIS (1995): «La place de l'autre. Remarques sur quelques emplois de ccontroversia) dans la rhétorique latine», en: Le Boulluec A. (Dir.), La controverse religieuse et ses formes, París, Cerf, pp. 29-46.

DELUCA, KEVIN (1999): «Unruly Arguments: The Body Rhetoric of Earth First ! Act Up and Queer Nation», en: Argumentation and Advocacy, $\mathrm{n}^{\circ}$ 36, pp. 9-21.

DUCHESNE, SOPHIE Y HAEGEL, FLORENCE (2003): «POlitisation et conflictualisation», en: Perrineau P. (Dir.), Le désenchantement démocratique, La Tour d'Aigues, Éditions de l'Aube, pp. 107-129. EBEL, MARIANNE Y FIALA, PIERRE (1983): Sous le consensus, la xénophobie. Paroles, arguments, contextes (1961-1981), Lausanne, Institut de science politique.

EEMEREN, FRANS VAN Y GARSSEN, BART (2008): «Controversy and confrontation in argumentative discourse», en: Eemeren F.H. van y Garssen B. (Dirs.), Controversy and Confrontation. Relating controversy analysis with argumentation theory, Amsterdam/Philadelphia, John Benjamins Publishing Company, pp. 1-26.

FARGE, ARLETTE (1992): Dire et mal dire au XVIIle siècle, París, Seuil.

FOUCAULT, MICHEL (1971): L'ordre du discours, París, Gallimard.

FRASER, NANCY ([1992] 2001): «Repenser la sphère publique: une contribution à la critique de la démocratie telle qu'elle existe réellement», en: Hermès, no 31, pp. 125-156.

GRAND ROBERT DE LA LANGUE FRANÇAISE (2001): «Controverse», Dictionnaire Le Robert, París, pp. 554. GUSFIELD, JOSEPH (2012 [1989]): «Significations disputées. Contester la propriété et l'autorité des problèmes sociaux», en: Cefaï D. y Terzi C. (Dirs.), L'expérience des problèmes publics, París, Éditions de l'EHESS, pp. 113-132.

GUSFIELD, JOSEPH ([1981] 2009): La culture des problèmes publics, París, Économica.

HABERMAS, JÜRGEN ([1962] 1978): L'espace public. Archéologie de la publicité comme dimension constitutive de la société bourgeoise, París, Payot.

JACQUIN, JÉRÔME (2011): «Le/La polémique: une catégorie opératoire pour une analyse discursive et interactionnelle des débats publics?», en: Semen, n³1, pp. 43-60.

JULLIARD, VIRGINIE Y CERVULLE, MAXIME (2013): «Différence des sexes et controversies médiatiques: du débat sur la parité au mariage pour tous (1998-2013)», en: Le Temps des médias, $n^{\circ}$ 21, pp. 161-175.

KERBRAT-ORECCHIONI, CATHERINE (1980): «La polémique et ses définitions», en: Le discours polémique, Lyon, PUL, pp. 3-40.

KRIEG-PLANQUE, ALICE (2009): La notion de «formu- 
le» en analyse du discours. Cadre théorique et méthodologique, Besançon, Presses Universitaires de Franche-Comté.

LABORDE, CÉCILE (2008): Critical Republicanism. The Hijab Controversy in Political Philosophy, Oxford, Oxford University Press.

LATOUR, BRUNO ([1989] 2005): La science en action. Introduction à la sociologie des sciences, París, la Découverte.

LEMIEUX, CYRIL (2007): «À quoi sert l'analyse des controverses?», en: Mil neuf cent, $\mathrm{n}^{\circ} 25, \mathrm{pp}$. 191-212.

LILTI, ANTOINE (2007): «Querelles et controverses. Les formes du désaccord intellectuel à l'époque moderne», en: Mil neuf cent, $\mathrm{n}^{\circ} 25$, pp. 13-28. LYOTARD, JEAN-FRANÇOIS (1983): Le Différend, París, Minuit.

MAINGUENEAU, DOMINIQUE ([1996] 2009): Les termes clés de l'analyse de discours, París, Seuil.

MOUFFE, CHANTAL (1994): Le politique et ses enjeux. Pour une démocratie plurielle, París, MAUSS. MULLER, PIERRE Y SUREL, YVES ([1998] 2000): L'Analyse des politiques publiques, París, Montchrestien. PESTRE, DOMINIQUE (2007): «L'analyse de controverses dans l'étude des sciences depuis trente ans", en: Mil neuf cent, $n^{\circ} 25$, pp. 29-43.

PHILLIPS, KENDALL (1999): «A Rhetoric of Controversy», en: Western Journal of Communication, $n^{\circ}$ 63, pp. 488-510.

PLANTIN, CHRISTIAN (2003): «Des polémistes aux polémiqueurs», en: Murat M., Declercq G. y Dangel J. (dirs.), La parole polémique, París, Champion, pp. 377-408.

PLANTIN, CHRISTIAN (2002): «Argument», en: Charaudeau P. et Maingueneau D. (dirs.), Dictionnaire d'analyse de discours, París, Seuil.

RAYNAUD, DOMINIQUE (2003): Sociologie des controverses scientifiques, París, PUF.

RENNES, JULIETTE (2016): «Cochères parisiennes.
Le risque en spectacle», en: Travail, Genre et Sociétés, no 36, pp. 37-59.

RENNES, JULIETTE (2011a): «Les formes de la contestation. Sociologie des mobilisations et théories de l'argumentation», en: A contrario, $n^{\circ} 16, \mathrm{pp}$. 151-173.

RENNES, JULIETTE (2011b): «llégitimer des distinctions en droit», en: Politix, nº 94, pp. 35-57. RENNES, JULIETTE (2007a): Le mérite et la nature. Une controverse républicaine, l'accès des femmes aux professions de prestige (1880-1940), París, Fayard.

RENNES, JULIETTE (2007b): «Analyser une controverse», en: Bonnafous S. y Temmar M. (dirs.), Analyse de discours et sciences humaines et sociales, París, Ophrys, pp. 91-107.

RENNES, JULIETTE (2007c): "Les controverses d'égalité en droit», en: Badie B. y Déloye Y. (Dirs.), Le temps de l'État, París, Fayard, pp. 408-419. SCOTTO D'APOLLONIA, LIONEL, LUXARDO, GIANCARLO Y PIET GREGORY (2014): «Approche lexicométrique des controverses climatiques», Communication aux JADT 2014. Disponible en: https://hal.archives-ouvertes.fr/hal-01139755 (último ingreso: 02/12/2019).

SMADJA, DAVID (dir.) (2012): Dossier «Penser la controverse», en: Raisons politiques, no 47.

STAMBOLIS-RUHSTORFER, MICHEL (2015): La culture du savoir: la construction de "l'expertise» dans les débats politiques sur le mariage et la filiation pour les couples de même sexe en France et aux États-Unis, Tesis de Doctorado en Sociología, EHESS/UCLA.

TERZI, CÉDRIC Y BOVET, ALAIN (2005): «La composante narrative des controverses politiques et médiatiques», en: Réseaux, no 132, pp. 111-132.

THOMPSON, JOHN (2000): Political Scandal. Power and Visibility in the Media Age, Cambridge, Polity Press. 